\title{
Effects of alcohol and marijuana on dynamic visual acuity: I. Threshold measurements
}

\author{
BRIAN BROWN \\ Smith-Kettlewell Institute of Visual Sciences, San Francisco, Califormia 94115 \\ ANTHONY J. ADAMS \\ School of Optometry, University of California, Berkeley, California 94720 \\ GUNILLA HAEGERSTROM-PORTNOY \\ Smith-Kettlewell Institute of Vioual Sciences, San Francisco, Califormia 94115 \\ REESE T. JONES \\ Langley Porter Neuropsychiatric Institute, University of Califormia, San Francisco, Califormia 94143 \\ and \\ MERTON C. FLOM \\ School of Optometry, University of California, Berkeley, California 94720

\begin{abstract}
Alcohol and marijuana produce significant dose-related reductions in dynamic visual acuity. Ten subjects participated in a double-blind experiment involving three dose levels of each drug (including placebo). The reduction of DVA produced by alcohol $(1.0 \mathrm{ml} 95 \%$ ethanol $/ \mathrm{kg}$ body weight) was greater than for marijuana (15 $\mathrm{mg} \Delta-9$-tetrahydrocannabinol), and we suggest that this difference was produced by differential oculomotor effects of the two drugs. We have speculated that reduction in DVA under alcohol may be a contributing factor in alcohol-related traffic accidents.
\end{abstract}

Dynamic visual acuity (DVA), the resolution of detail in moving targets, is a complex task involving precise sensory and motor coordination. It is important in such practical situations a driving and flying; for example, Burg (Note 1, Note 2) has shown that DVA is significantly correlated with accident record, particularly for collisions where vehicles come from the side. In such collisions, it might be expected that detection, tracking, identification, and prediction of the path of the other vehicle would be of importance.

The components involved in DVA are (a) static visual acuity, (b) ocular pursuit of the moving target by a combination of fast (saccadic) eye movements and slower (pursuit) eye movements, and (c) interpretation of the target image which may be moving on the retina at some distance from the fovea. Ludvigh and Miller (1958) have shown that good static acuity is a necessary, but not sufficient, condition for good DVA. It has been shown that the observed decrement in acuity produced as the target angular velocity is increased can be accounted for by the inability of the

This research was supported by Contract No. DADA 17-73-C 3106 from the U.S. Army Medical Research and Development Command to the Visual Sciences Division of the Optical Sciences Group, San Rafael, California, and by National Institutes of Health Grants K02MH32904 and DA00033 to R.T.J. oculomotor system to stabilize the target image on the retina (Brown, 1972a).

In our current work (in preparation), we have shown substantial decrements of oculomotor tracking of sinusoidally moving targets in alcohol-intoxicated subjects. These performance decrements were seen in both the saccadic and the pursuit-eye-movement systems, and thus, in drug-intoxicated subjects, larger errors of both position and velocity of the target image on the retina were produced. Smaller deficits in tracking were seen in the marijuana-intoxicated subjects. We expected these reductions of tracking performance to produce decreased DVA in subjects under the influence of alcohol and to a lesser extent in subjects under marijuana. DVA measurements of 10 subjects at two target contrasts using two doses of alcohol, two doses of marijuana, and a placebo in a double-blind experiment are reported here.

\section{METHOD AND APPARATUS}

Landolt rings (ranging in size from 1.0 to $11.6 \mathrm{~min}$ of arc corresponding to Snellen letter sizes $20 / 20$ to $20 / 232$ ) were projected at two contrast levels $(49 \%$ and $12 \%)$ at velocities of $0,5,15,25$, and $40 \mathrm{deg} / \mathrm{sec}$. The targets were brighter than the background. The use of a projection system required that targets with negative contrasts be used, since projection of a background to the target would produce undesired changes in adaptation level and the edges of the projected area would give additional cues to the 


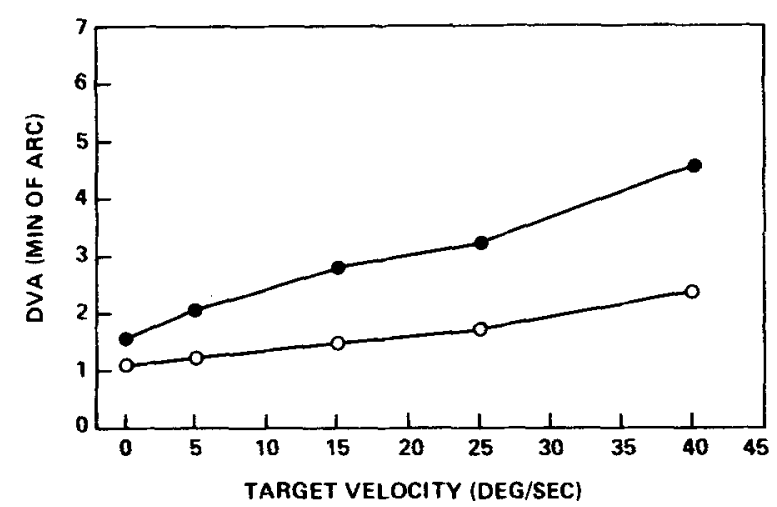

Figure 1. Dynamic visual acuity prior to drug ingestion as a function of target velocity for contrast levels of $49 \%(O)$ and $12 \%$ $(\bullet)$. Each point represents 50 threshold determinations (5 sessions $x$ 10 subjects).

oculomotor system for target tracking. Targets were projected by means of a series of mirrors onto a white hemicylindrical screen, $9 \mathrm{ft}$ in radius, with a luminance of $16.2 \mathrm{~cd} / \mathrm{m}^{2}$. They were moved horizontally by applying an appropriate ramp voltage to the galvanometer on which one of the mirrors was mounted. The subject sat at the center of curvature of the screen with his head restrained and his left eye occluded. He held fixation steady (with the aid of a fixation mark) betwen presentations. The initial target position was always at the fixation point, and targets moved to the subject's right. Randomly oriented targets were presented, for $500 \mathrm{msec}$ at random times (between 0.5 and $1.5 \mathrm{sec}$ ) after a warning tone.

Threshold was determined using the method of limits and was calculated by averaging one descending and one ascending determination. The subject responded by pressing buttons corresponding to the four gap positions used (U, D, R, L). [Methling (1970) has shown that there is no difference in perception of horizontal or vertical gaps for targets moving at velocities less than $60 \mathrm{deg} / \mathrm{sec}$. but at greater target velocities, horizontal target gaps are more easily discriminated.] The criterion used for ending a threshold determination was two successive correct or incorrect responses (for ascending and descending procedures. respectively).

Eye movements were recorded on magnetic tape during the DVA determinations: results of the analysis of these data will be reported in a separate communication.

\section{Experimental Design}

The drug and placebo treatments were administered doubleblind. using a replicated, balanced $5 \times 5$ Latin square design; thus. 10 subjects were used. The five experimental conditions were 0.5 and $1.0 \mathrm{ml} / \mathrm{kg}$ body weight of $95 \%$ ethanol, 8 and $15 \mathrm{mg}$ $\Delta$-9-tetrahydrocannabinol (THC), and a placebo.

\section{Subjects}

The subjects were paid volunteers (aged from 18 to 28 , weighing from 64 to $104 \mathrm{~kg}$ ) all of whom were "social drinkers," had previously smoked marijuana at least five times, and were currently smoking two to five marijuana cigarettes per week. They all had $20 / 20$ vision (corrected when necessary). They had been sereened by a psychiatrist and informed of possible adverse effects of alcohol and marijuana.

\section{Drug Administration}

Subjects were required both to drink and smoke, but were given only one experimental drug at each session (i.e., if a subject was given alcohol to drink, he was given a marijuana placebo to smoke. and vice versa). This design is quite successful in keeping the subject unaware of which drug was administered. Many subjects were unable to tell whether they had drunk alcohol or smoked marijuana, especially at the low doses. Many were convinced that they had been given both drugs. Jones (1971) has shown that the experimental situation is an important determinant of the subjective effects of marijuana. To approximate the social conditions under which these drugs are used, subjects drank and smoked in a comfortably furnished room and the experimenters maintained friendly relations with them during the experiment.

Ethanol was mixed with fruit juice and two ice cubes and drunk through a straw from a lidded paper cup: two drops of ethanol and two drops of eucalyptus oil were placed on the lid of the cup to minimize olfactory cues to the presence of alcohol. Blood alcohol levels were monitored with an "Intoxilizer" (Omicron Systems Corporation, Palo Alto), which determines alcohol content of a breath sample using infrared spectroscopy.

THC $(8$ or $15 \mathrm{mg}$ ) was provided in $0.8-\mathrm{g}$ cigarettes (provided by the National Institute on Drug Abuse), which were smoked for maximum intake in about $10-15 \mathrm{~min}$. During the experiment, subjects were asked to rate how "high" they felt on a $0-100$ scale where 0 is normal and 100 is as high as they had ever been on alcohol or marijuana. Pulse rates were also measured.

\section{RESULTS}

\section{Relationship Between DVA and Target Angular Velocity}

Figure 1 shows DVA as a function of target angular velocity for all predrug sessions in the present experiment; there are 50 threshold determinations at each point ( 5 sessions $\times 10$ subjects). The relationship between DVA and target velocity is linear over the range of target velocities used here. Straight lines fitted to the data account for $97.3 \%$ and $98.6 \%$ of the variance for high- and low-contrast data, respectively. The essentially linear relationship between DVA and target velocities up to $40 \mathrm{deg} / \mathrm{sec}$ is in agreement with studies by Brown (1972a) and Fergenson and Suzansky (1973). Ludvigh and Miller (1958) proposed that DVA varies as the cube of target angular velocity, but it is clear that for these lower target velocities a straight line describes the data very well.

\section{Time Course of Alcohol and Marijuana Effects on DVA}

Threshold size increased by $40 \%$ for the high-contrast targets and by $25 \%$ for the low-contrast targets $30 \mathrm{~min}$ after ingestion of $1.0 \mathrm{ml} / \mathrm{kg}$ ethanol. The low dose of alcohol and both doses of marijuana produced smaller changes. Significance levels (Walsh test) for each of the drug-induced changes at this first postdrug measurement are shown in Table 1.

The time course of DVA (collapsed over all target velocities) at the two contrast levels as well as blood alcohol levels, pulse rates, and subjective "high" ratings for all five treatment conditions are shown in Figure 2. Table 2 shows significance levels associated

Table 1

Walsh Test Probabilities for (Post 1-PRE) DVA Measures in Figure 2

\begin{tabular}{|c|c|c|c|c|c|}
\hline \multirow[b]{2}{*}{ Contrast } & \multicolumn{2}{|c|}{$\begin{array}{l}\text { Alcohol } \\
(\mathrm{ml} / \mathrm{kg})\end{array}$} & \multicolumn{2}{|c|}{$\begin{array}{l}\text { Marijuana } \\
\text { (mg THC) }\end{array}$} & \multirow{2}{*}{$\begin{array}{l}\text { Pla- } \\
\text { cebo }\end{array}$} \\
\hline & .5 & 1.0 & 8 & 15 & \\
\hline Low $(12 \%)$ & $<.011$ & $<.004$ & n.s. & n.s. & n.s. \\
\hline High $(49 \%)$ & n.s. & $<.027$ & $<.056$ & $<.025$ & n.s. \\
\hline
\end{tabular}


ALCOHOL
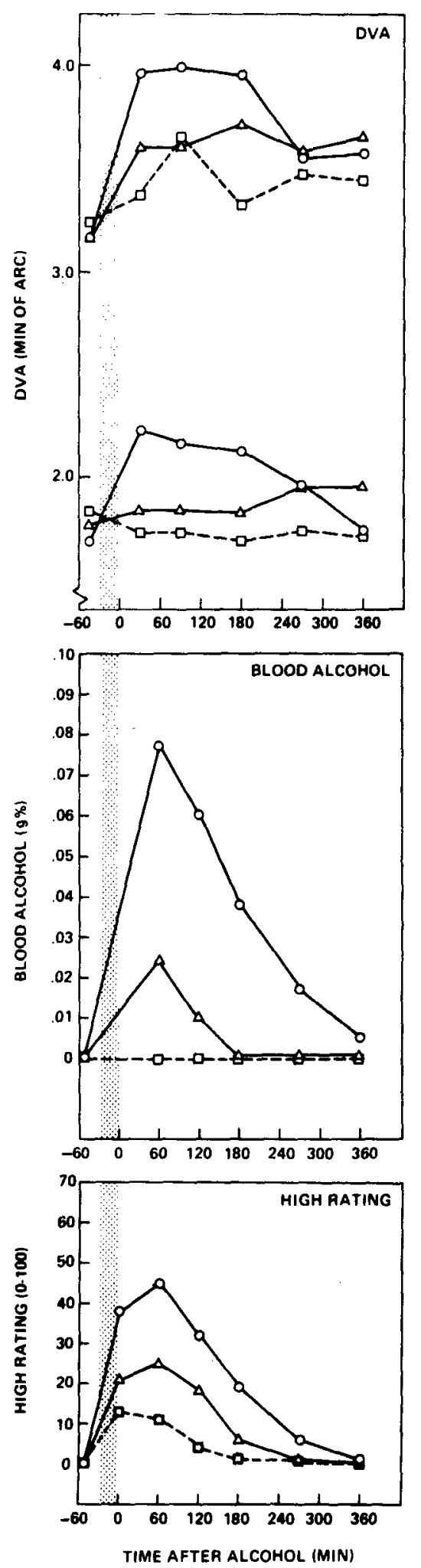

MARIJUANA
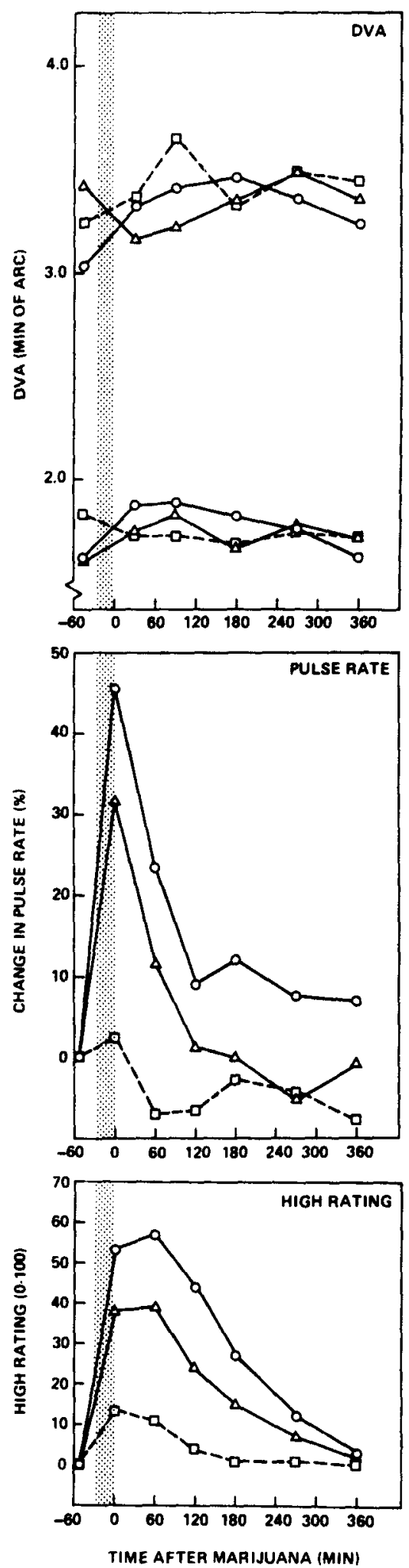

Flgure 2. In the upper panels, dynamic vibual acuity (collapwed across target apeeds and subjects) is ahown as a function of time after Ingestion of alcohol or martjuana, for targets of low contrat (apper sets of currea) and high contrast (lower sets of curves). For alcohol: $1.0 \mathrm{ml} / \mathrm{kg}$ body weight of $95 \%$ thanol $(0) ; 0.5 \mathrm{ml} / \mathrm{kg}$ body welght of $95 \%$ ethanol $(\Delta)$; phacebo (D). For marlluana: $15 \mathrm{mg}$ THC (O); $8 \mathrm{mg}$ THC $(\Delta)$; placebo $(\square)$. The time course of blood alcohol levels and pulse rates for the two druge (center panels) and the thine coure of the subjects" "high" ratings (lower panels) are also shown. The shnded area indleates the time of drug ingeation. 
Table 2

Significance Levels for DVA of Figure 2 Using Friedman Two-Way Analysis of Variance (Time Course of Drug Effect by Subjects)

\begin{tabular}{lcccccc}
\hline & \multicolumn{2}{c}{$\begin{array}{c}\text { Alcohol } \\
(\mathrm{ml} / \mathrm{kg})\end{array}$} & & \multicolumn{2}{c}{$\begin{array}{c}\text { Marijuana } \\
(\mathrm{mg} \text { THC })\end{array}$} & \\
\cline { 2 - 3 } Contrast & 5 & 1.0 & & 8 & 15 & $\begin{array}{c}\text { Pla- } \\
\text { cebo }\end{array}$ \\
\hline Low $(12 \%)$ & $<.05$ & $<.02$ & & n.s. & n.s. & n.s. \\
High $(49 \%)$ & n.s. & $<.05$ & n.s. & $<.01$ & n.s. \\
\hline
\end{tabular}

with each DVA time course (determined using Friedman two-way analysis of variance). DVA after alcohol $(1.0 \mathrm{ml} / \mathrm{kg})$ at high-and low-contrast levels decreased substantially, and this decrement persisted tor 4 to $5 \mathrm{~h}$ after drinking. Recovery to predrink DVA occurred within $6 \mathrm{~h}$ after drinking. essentially following the blood alcohol time course. For the $0.5 \mathrm{ml} \mathrm{kg}$ alcohol dose, a significant decrement in DVA was shown for low-contrast targets (see Table 2).

The marijuana data for high-contrast targets show a clear and significant treatment effect for the $15-\mathrm{mg}$ THC dose and a less marked, nonsignificant, effect for the $8-\mathrm{mg}$ THC dose. The low-contrast data for marijuana show greater variance that the highcontrast data. The 15-mg THC dose produces a decrease in acuity with recovery by the end of the testing period: the lack of statistical significance may only retlect the higher variance in these low-contrast data. The improvement in acuity seen with the $8-\mathrm{mg}$ THC dose also failed to reach statistical significance.

The alcohol and marijuana doses were chosen to give equivalent subjective "high" ratings. It is apparent from Figure 2 that this was not so for this group. The marijuana doses produced peak high ratings at least $25 \%$ greater than the corresponding alcohol dose. In spite of this, the alcohol-induced decrements of DVA were generally greater than those produced by marijuana.

The blood alcohol level (BAL) curves shown in Figure 2 peak 45 to $60 \mathrm{~min}$ after the end of the drinking period. The recovery phase for the $1.0 \mathrm{ml} / \mathrm{kg}$ dose indicates decline in BAL at a rate of $0.015 \mathrm{~g} \%$, which agrees well with previous work. [See Wallgren and Barry (1970, p. 48) for a summary of these studies.] The DVA decrement was still evident for both high- and low-contrast targets when the BAL had fallen to approximately $0.04 \%$, and recovery to normal levels of DVA did not begin until about $3 \mathrm{~h}$ after drinking.

The pulse rate for the marijuana treatments shows an early peak with rapid decline which is a typical effect of the drug. The mean pulse rate is close to presmoke levels within $2 \mathrm{~h}$ after smoking. In contrast, the high ratings for marijuana show a substantially delayed time course with respect to the pulse rates and are comparable in time course to the high rating for alcohol.

\section{Dose Relationships and DVA}

The decrease in performance for subjects under alcohol is linearly related to dose for both target contrasts. This is also true for marijuana at high target contrast. For high-contrast targets, the decrement in DVA from the placebo (zero dose) level for the $1.0 \mathrm{ml} / \mathrm{kg}$ alcohol dose is almost twice that for the 15-mg THC dose. despite the fact that the alcohol was less effective in producing a subjective high. Figure 3 shows the relationship between drug dose and change in DVA (for both target contrasts) $30 \mathrm{~min}$ after drug administration. The $1.0-\mathrm{ml} / \mathrm{kg}$ dose of alcohol produced significant decrements in DVA for both high- and - low-contrast targets $(\mathrm{p}<.022$, $\mathrm{p}<.012$. respectively. Walsh test). The $15 \mathrm{mg}$ THC dose also produced significant decrements for highand low-contrast targets $(\mathrm{p}<.004, \mathrm{p}<.051$. respectively. Walsh test).

\section{Alcohol and Marijuana Effects as a Function of Target Velocity}

We have already indicated the significant decrement in DVA produced by both the high alcohol and high marijuana dose. That the alcohol-induced
Figure 3. Change in dynamic visual acuity $30 \mathrm{~min}$ after ingestion of alcohol or marijuana for high-contrast $(O)$ and low-contrast $(O)$ targets as a function of drug dose.
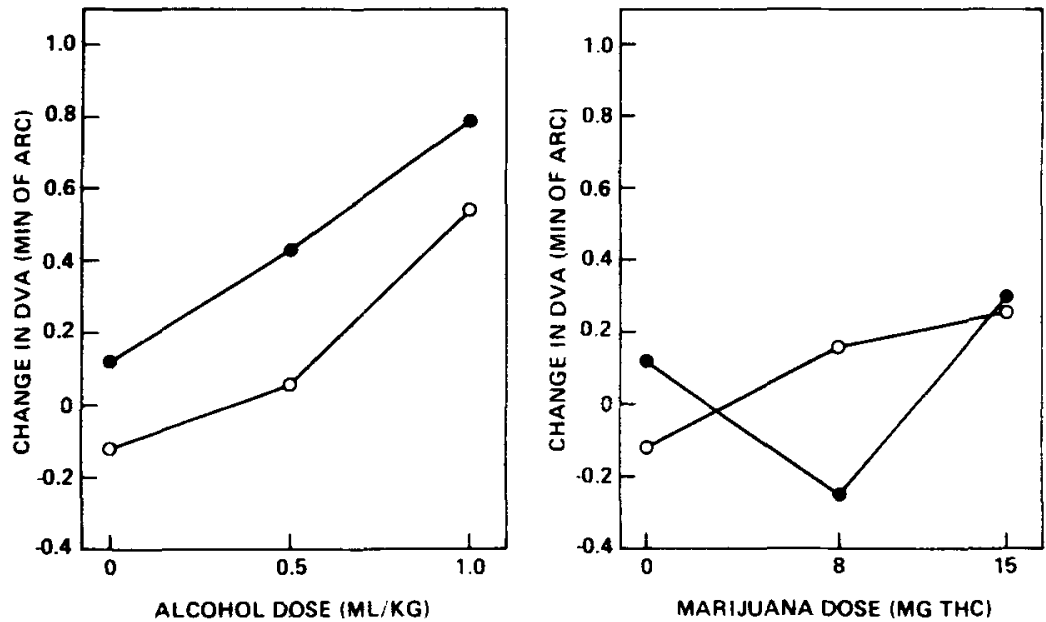
decrement is greater than that for marijuana is clearly shown in the time course data. The alcohol-induced decrement (with respect to placebo) increased as a function of target angular velocity, while no such trend is evident for marijuana; this is illustrated in Figure 4. which shows DVA as a function of target angular velocity for high- and low-contrast targets $30 \mathrm{~min}$ after $1.0 \mathrm{ml} / \mathrm{kg}$ ethanol and $15 \mathrm{mg} \mathrm{THC}$. The greater decrement with increased target velocity is probably due to reduced eye-movement performance under alcohol which resulted in target images moving on the retina at greater mean distances from the fovea. Furthermore. when eye movements were not required for target recognition, i.e.. when target velocity was zero (equivalent to a static acuity measure). there was no statistically demonstrable drug effect for either alcohol or marijuana.

\section{DISCUSSION}

DVA was clearly reduced by alcohol and marijuana in the experiment reported here. Thirty minutes after drinking $1.0 \mathrm{ml} / \mathrm{kg}$ body weight of alcohol. average DVA was reduced by $0.54 \mathrm{~min}$ of arc for high-contrast targets and by $0.79 \mathrm{~min}$ of arc for low-contrast targets. Thirty minutes after smoking a cigarette containing $15 \mathrm{mg}$ THC. DVA was reduced by $0.30 \mathrm{~min}$ of arc for high-contrast targets and by $0.38 \mathrm{~min}$ of arc for low-contrast targets.

Honegger. Kampschulte. and Klein (1970), in an attempt to develop a test of oculomotor coordination without direct eye-movement measurement, presented Landolt rings moving in a circle around the fixation axis. By continuously reducing the speed of the target. they determined "threshold speed for recognition" of Landolt ring gap orientation. The velocity threshold for detection was reduced by low alcohol doses with no demonstrable dose relationship. Inasmuch as "threshold speed" changes reflect changes in acuity, their results are consistent, but not directly comparable. with ours.

Good static acuity is needed to achieve good DVA (Ludvigh \& Miller. 1958). and static acuity was unaltered by any of our experimental treatments. This leads us to infer that the reduced DVA which we have shown is related to the subject's oculomotor behavior when pursuing moving targets. This speculation is supported by the data of Figure 4, which demonstrate differential speed effects on DVA; the data imply that the faster the target moves, the more difficulty an intoxicated subject will have in stabilizing the target image on the retina. Loss of acuity for moving targets is produced by displacement of the target image from the fovea combined with movement of the target image across the retina (Brown, 1972b). Under conditions of drug intoxication, a number of factors may produce these effects. Increased reaction time will produce a greater initial displacement of the target from the fovea before any corrective movement is made. Decrease in the size of corrective saccades or decreased saccadic velocity will mean that a greater displacement of the target image from the fovea remains after the saccadic movement. Decrease in smooth pursuit movement velocity will produce greater retinal target image velocity.

Blood alcohol levels of about $0.08 \mathrm{~g} \%$ have been reported to increase manual reaction time by $10 \%-15 \%$ (Wallgren \& Barry, 1970). We assume that oculomotor reaction time will increase similarly and thus produce greater displacement between target image and fovea before a correctional movement is initiated. No such changes in manual reaction time have been shown for marijuana (LeDain, 1972). We have been unable to find data in the literature on the relative accuracy of correctional saccadic eye movements with alcohol or marijuana intoxication. We have shown that in an oculomotor tracking task. the maximum velocity at which the subject can follow a sinusoidally moving target using both saccades and smooth pursuit movement is substantially decreased under alcohol. but significant effects are not demonstrable for marijuana in simple stimulus configurations. The eye movements required to perform this sinusoidal tracking task are clearly related to the eye movements required for good DVA (i.e., maintenance of foveal fixation and minimizing retinal image "slip"). The relatively large change in DVA with alcohol and the smaller change with marijuana is consistent with the change in tracking eye movements under the two drugs, suggesting that the differential effects of alcohol and marijuana on DVA may be understood in terms of differences in eyemovement performance on the two tasks.
ALCOHOL

Figure 4. On the left, dynamic visual acuity is shown as a function of target velocity $30 \mathrm{~min}$ after drinking alcohol (-) or placebo (- - -) for targets of low contrast (solid symbols) and high contrast (open symbols): $1.0 \mathrm{ml} / \mathrm{kg}$ body weight of $95 \%$ ethanol $(E)$ : placebo (c). The right-hand side of the figure shows the corresponding relationship after smoking marijuana or placebo: $15 \mathrm{mg}$ THC $(:)$, placebo ( $\overline{\text { ) }}$.
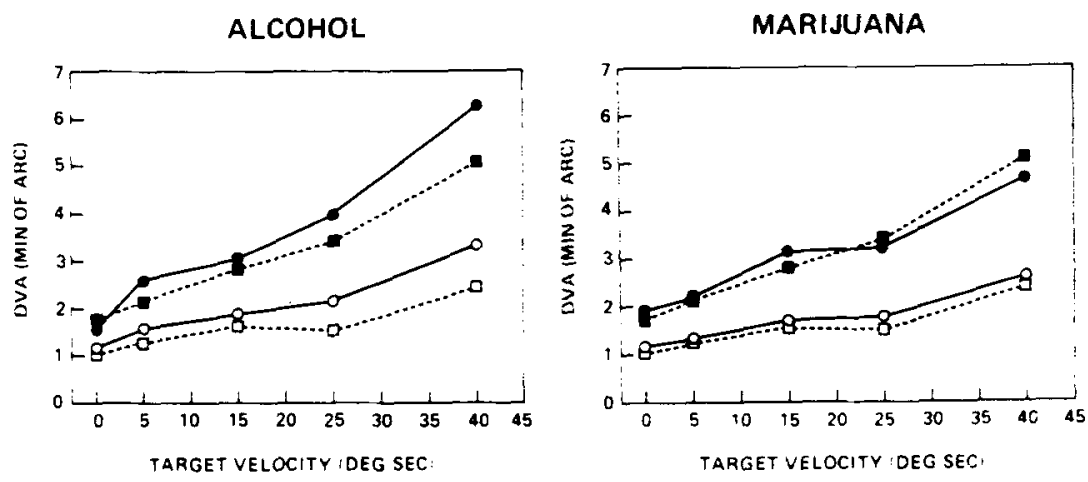
Regardless of the mechanism involved, the reduction of DVA with alcohol and marijuana is relevant in tasks such as driving. Many traffic accidents are alcohol-related; Carlson (1972) has reported that between $15 \%$ and $50 \%$ of single vehicle accidents involve alcohol (the percentage varies significantly as a function of time of day, peaking at approximately $3 \mathrm{a} . \mathrm{m}$.). Perception of low-contrast objects moving relative to the driver is expected to be important in the night-time driving situation, and thus DVA reduction after alcohol ingestion may be a partial cause of alcohol-related accidents. Burg (1968) investigated a large number of vision functions, including static visual acuity and depth perception, and found dynamic visual acuity to correlate best with accident records. Further, Burg (1974) reanalyzed these data to correlate vision functions with specific accident types and showed improved correlations between accident record and DVA when collision with vehicles approaching from either the right or the left side were considered alone. This suggests that "individuals with poor ability to detect and track objects coming into their path from the left or right side experience more accidents" (Burg, Note 2), p. 37).

However convincing this argument, the evidence for a link between DVA and driving performance is correlational and does not exclude a more general common factor that is alcohol-sensitive underlying both DVA performance and accident record. To the extent that alcohol causes traffic accidents through a reduction in DVA, the small reduction in DVA produced by marijuana could also be expected to lead to increased accident rates.

The way in which marijuana usage affects accident record has not been established. A number of studies of the effects of marijuana on driving performance indicate that marijuana intoxication (at dose levels similar to those used in this experiment) results in less skillful performance whether on simulators (Rafaelsen, Bech, Christiansen, Cristrup. Nyboe, \& Rafaelsen, 1973), in driving on test courses (Klonoff, 1974; LeDain, 1972), or driving in city and suburban traffic (Klonoff, 1974).

To summarize, alcohol and marijuana produced significant dose-related reductions in dynamic visual acuity. The reduction of DVA produced by alcohol was greater than for "equivalent" doses of marijuana, and we suggest that this difference was produced by differential oculomotor effects of the two drugs. We have speculated that since DVA correlates with accident record, reduction in DVA under alcohol may be an important contributing factor in alcohol-related traffic accidents.

\section{REFERENCE NOTES}

1. Burg. A. Vision test scores and driving record: Additional findings. University of California Report No. 68-27, 1968.

2. Burg, A. Visual degradation in relation to specific accident types. Final report, Institute of Transportation and Traffic Engineering. School of Engineering and Applied Science, University of California in Los Angeles. 1974. (UCLA-ENG-7419.)

\section{REFERENCES}

Brown. B. Dynamic visual acuity, eye movements and peripheral acuity for moving targets. Vision Research. 1972, 12. 305-321. (a)

Brown, B. Resolution thresholds for moving targets at the fovea and in the peripheral retina. Vision Research, 1972, 12, 293-304. (b)

Carlson, W. L. Alcohol usage of the nighttime driver. Journal of Safety Research, 1972, 4. 12.25.

Fergenson, P. E., \& Suzansky, J. W. An investigation of dynamic and static visual acuity. Perception, 1973, 2, 343-356.

Honegger, H., Kampschulte, R., \& Klein, H. Störung der Sehschärfe für bewegte Objekte durch Alkohol. Blutalkohol, 1970, 7. 31-44.

Jones, R. T. The marijuana induced 'social high': A note of caution. Proceedings of the Western Pharmacological Society, 1971, 14, 21-25.

Kronoff, H. Marijuana and driving in real-life situations. Science, 1974, 186. 317.324.

LeDain, G. (Ed.). Cannabis. A report of the commission of inquiry into the non-medical use of drugs. Ottawa: Information Canada, 1972.

Ludvigh, E. J., \& Miller, J. W. Study of visual acuity during the ocular pursuit of moving test objects. 1. Introduction. Journal of the Optical Society of America, 1958, 48, 799-802.

Methlisg, D. Über die unterschiedliche Erkennbarkeit von Landoltringöffnungen verschiedener Lage bei Augenfolgebewegungen. Vision Research, 1970, 10, 543-548.

Rafaelsen, O. J., Bech, P., Christiansen, J., Cristrup, H., Nrboe, J., \& Rafaelsen, L. Cannabis and alcohol: Effects on simulated car driving. Science, 1973, 179, 920-923.

Wallgren, H., \& Barry, H., III. Actions of alcohol. Biochemical physiological and psychological aspects (Vol. 1). Amsterd am: Elsevier. 1970.

(Received for publication June 20, 1975; accepted August 15, 1975.) 